УДК 629.113

UDC 629.113

\author{
Вербицький В.Г. ${ }^{1}$, Хребет В.Г. ${ }^{2}$, Місько С.М. ${ }^{3}$ \\ ${ }^{1}$ Запорізький національний університет, \\ ${ }^{2}$ Начіональний авіачійний університет, \\ ${ }^{3}$ Одеська державна академія будівниитвва та архітектури
}

\title{
БІФУРКАЦЙНИЙ ПІДХІД ДО АНАЛІЗУ ДИВЕРГЕНТНОЇ ВТРАТИ СТІЙКОСТІ НЕЛІНІЙНОЇ МОДЕЛІ КОЛІСНОГО ЕКІПАЖА ЗА НАЯВНОСТІ ПОСТІЙНОГО СИЛОВОГО ЗБУРЕННЯ
}

\begin{abstract}
Представлено біфуркаційний підхід до аналізу дивергентної втрати стійкості нелінійної моделі двохосьового екіпажа за наявності постійного силового збурення. За належної корекції кута повороту керованого колісного модуля екіпаж повертається до стійкого прямолінійного режиму руху. В роботі представлена залежність кута парирування від величини бокового збурення (функція керування суттєво залежить від нелінійних характеристик сил відведення моделі екіпажа). При лінеаризації сил бокового відведення запропонована функція керування співпадає із відомим співвідношенням, отриманим рядом авторів. На основі біфуркаційного підходу, який не потребує попереднього визначення множини стаціонарних станів моделі екіпажа, реалізовано відповідну методику побудови критичної множини параметрів керування (поздовжньої швидкості та кута повороту керованих коліс). При перетині критичної множини параметрів відбувається дивергентна втрата стійкості стаціонарного режиму, який гарантовано стійкий до моменту виходу на границю критичних значень параметрів керування. Критична множина параметрів має особливість - точку загострення та в малому околі цієї точки може бути представлена аналітично напівкубічною параболою. При зміні суттєвих конструктивних параметрів критична множина параметрів трансформується, що пов'язано із зміною характеру безпеки втрати стійкості прямолінійного руху. Показано, що умова безпечної-небезпечної втрати стійкості прямолінійного руху визначається співвідношенням між безрозмірними коефіцієнтами відведення на осях та коефіцієнтами зчеплення на осях екіпажа в поперечному напрямі. При цьому, коефіцієнти зчеплення не входять в лінеаризовану систему рівнянь збуреного руху, а відносяться до істотно нелінійної характеристики сил відведення.

біфуркації.

Ключові слова: динамічна система, колісний екіпаж, стаціонарні стани, стійкість, дивергентні
\end{abstract}

\section{ВСТУП}

Однією з головних властивостей динамічних і швидкісних легкових автомобілів є курсова стійкість руху, забезпечення якої багато в чому залежить від властивостей еластичних рушіїв. Конструктивними змінами шини, можна покращувати курсову стійкість руху автомобіля.

Однією з головних властивостей динамічних і швидкісних легкових автомобілів $є$ курсова стійкість руху, забезпечення якої багато в чому залежить від властивостей еластичних рушіїв. Конструктивними змінами шини, можна покращувати курсову стійкість руху автомобіля.

Природно, що різноманітність нелінійних пружних властивостей сучасних шин, що задаються конструктивно, стимулює розвиток відповідних «тонших» методів аналізу, здатних вловити вплив відповідних властивостей рушіїв на динамічні якості усього екіпажа.

ЦІЛЬ ТА ЗАДАЧІ ДОСЛІДЖЕННЯ

Метою роботи є аналіз дивергентної втрати стійкості нелінійної моделі колісного екіпажа при наявності постійного силового збурення на основі біфуркаційного підходу.

АНАЛІЗ ЛІТЕРАТУРНИХ ДАНИХ ТА ПОСТАНОВКА ПРОБЛЕМИ

Розглянемо одномасову «велосипедну» модель екіпажа із закріпленим рульовим управлінням [6, 7]. Розрахункова схема такої моделі представлена на рис.1.

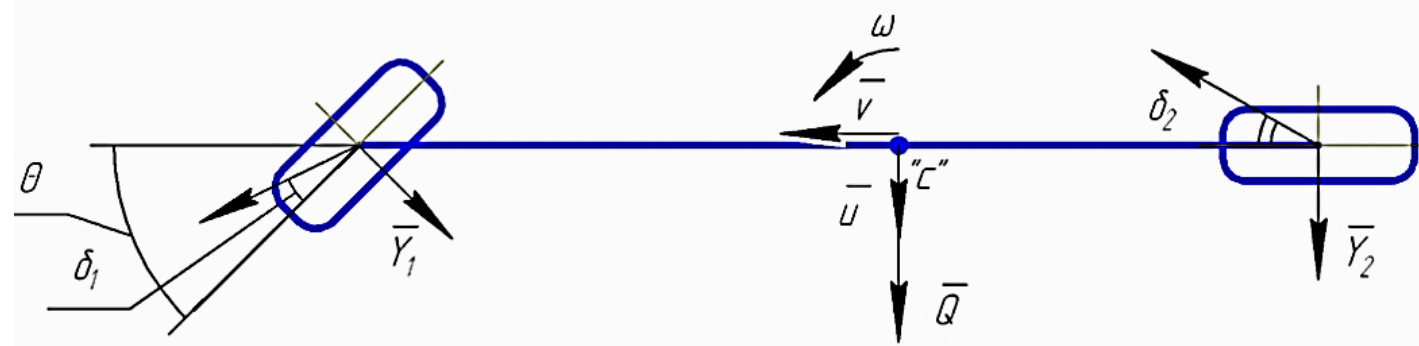

Рисунок 1. - Розрахункова схема екіпажа

Рівняння руху моделі мають вигляд (передбачається $\cos (\theta) \approx 1)$ : 


$$
\left\{\begin{array}{l}
m(\dot{u}+V \omega)=Y_{1}\left(\delta_{1}\right)+Y_{2}\left(\delta_{2}\right)+Q \\
J \dot{\omega}=a \cdot Y_{1}\left(\delta_{1}\right)-b \cdot Y_{2}\left(\delta_{2}\right)
\end{array}\right.
$$

де $V, u$-поздовжня і поперечна швидкості центру мас автомобіля; $\omega$ - кутова швидкість відносно вертикальної осі; $\theta$ - кут повороту передніх коліс; $m, J$ - маса та центральний момент інерції системи відносно вертикальної осі; $a, b$ - відстані від центру мас до передньої та задньої колісних осей відповідно; $Y_{1}, Y_{2}-$ нелінійні характеристики сил відведення; $Q$ - зовнішня бічна сила, прикладена до автомобіля в центрі мас.

Кути відведення на осях визначаються співвідношеннями:

$$
\left\{\begin{array}{l}
\delta_{1}=\theta-\frac{u+a \omega}{V} \\
\delta_{2}=\frac{-u+b \omega}{V} .
\end{array}\right.
$$

Надалі, з метою спрощення математичних перетворень, введемо безрозмірні величини:

$$
Y_{i}=\overline{Y_{i}} N_{i}, \bar{Q}=\frac{Q}{m g}, N_{1}=\frac{m g b}{l}, N_{2}=\frac{m g a}{l} .
$$

Рівняння, що визначають стаціонарні стани системи за наявності поперечної зовнішньої сили $Q$, мають вигляд:

$$
\left\{\begin{array}{l}
\frac{V \omega}{g}=\overline{Y_{1}} \frac{b}{l}+\overline{Y_{2}} \frac{a}{l}+\bar{Q} \\
\overline{Y_{1}}-\overline{Y_{2}}=0
\end{array}\right.
$$

В другому рівнянні системи (4) перейдемо до обернених функцій $\delta_{1}=G_{1}(\bar{Y})$ і $\delta_{2}=G_{2}(\bar{Y})$, де $\bar{Y}-$ безрозмірна бокова сила на передній та задній осях екіпажа стає новим незалежним аргументом. У цьому випадку від системи (4) можна перейти до одного визначального рівняння:

$$
G(\bar{Y})=\frac{g l}{V^{2}} \cdot(\bar{Y}+\bar{Q})-\theta
$$

де функція $G(\bar{Y})=\left(\delta_{2}-\delta_{1}\right)$.

Зважаючи на геометричну інтерпретацію розв'язання рівняння (5), його дискримінантна множина $€$ геометричним місцем точок у площині параметрів управління $(V, \theta)$, для яких пряма $\frac{g l}{V^{2}} \cdot(\bar{Y}+\bar{Q})-\theta$ дотична до кривої $G(\bar{Y})$.

У параметричній формі дискримінантна крива задається системою (6)

$$
\left\{\begin{array}{l}
\frac{g l}{V^{2}}=G^{\prime}(\bar{Y}) \\
\theta=G^{\prime}(\bar{Y}) \cdot(\bar{Y}+\bar{Q})-G(\bar{Y}) .
\end{array}\right.
$$

Далі з'ясуємо умови реалізації прямолінійного режиму руху екіпажа при дії постійного силового збурення. В цьому випадку повне доцентрове прискорення віднесене до прискорення вільного падіння дорівнює сумі $\bar{Y}+\bar{Q}$, отже для реалізації прямолінійного режиму потрібно виконання умови $\bar{Y}+\bar{Q}=0$.

З останнього виходить

$$
\bar{Y}=-\bar{Q} \Rightarrow G(Y)=\left(\delta_{2}-\delta_{1}\right)=G(-\bar{Q}) .
$$


а враховуючи, що при $\omega=0$ справедлива рівність $\theta=-\left(\delta_{2}-\delta_{1}\right)$, приходимо до співвідношення (8)

$$
\theta=-G(-\bar{Q})
$$

(той самий результат можна отримати безпосередньо з рівняння (5)).

У випадку непарної функції $G(\bar{Y})$ маємо $\theta=G(\bar{Q})$. Лінеаризація останнього (в околі нуля) дає цікавий наслідок

$$
\theta=\frac{k_{1}-k_{2}}{k_{1} \cdot k_{2}} \bar{Q}=\frac{g \cdot l}{V^{+^{2}}} \bar{Q} .
$$

\section{РЕЗУЛЬТАТИ ДОСЛІДЖЕНЬ}

На рис. 2 проілюстровано графічний метод визначення кута парирування. Стаціонарний режим $O_{1}$, що відповідає прямолінійному режиму руху, отримуємо шляхом зміщення рухомої прямої по вертикалі на величину кута корекції $\theta=G(\bar{Q})$.

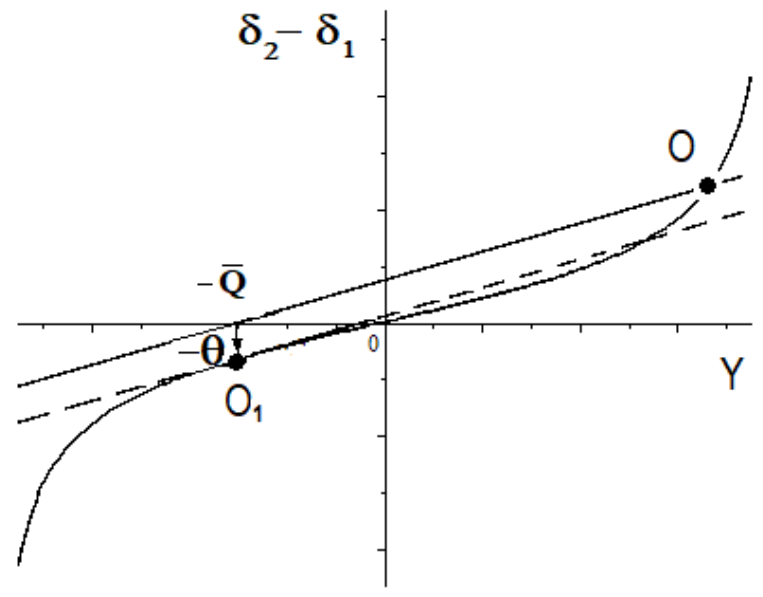

Рисунок 2. - Графічне визначення кутів парирування при дії зовнішньої бічної сили: геометрична картина вибору кута корекції.

Далі визначимо аналітичні умови стійкості прямолінійного режиму руху при постійному силовому збуренні. Враховуючи умову $\bar{Y}+\bar{Q}=0$, із системи (6) отримаємо критичні параметри, за яких відбувається дивергентна втрата стійкості прямолінійного режиму

$$
\begin{aligned}
& \theta=-G(-\bar{Q}) ; \\
& V^{2}=\frac{g l}{G^{\prime}(-\bar{Q})}
\end{aligned}
$$

Нижче наведено наближення для (9) у вигляді розкладання в ряди за степенями малого параметра $\bar{Q}$, для випадку обраних в роботі нелінійних залежностей сил відведення:

$$
\begin{aligned}
& \bar{Y}_{i}=\frac{k_{i} \cdot \delta_{i}}{\left(1+\left(\frac{k_{i} \cdot \delta_{i}}{\varphi_{i}}\right)^{2}\right)^{1 / 2}} ; \\
& \theta \approx\left(\frac{1}{k_{2}}-\frac{1}{k_{1}}\right) \cdot \bar{Q}+\left(\frac{1}{2 k_{2} \cdot \varphi_{2}^{2}}-\frac{1}{2 k_{1} \cdot \varphi_{1}^{2}}\right) \cdot \bar{Q}^{3} \\
& \theta \approx \frac{g \cdot l}{V^{+{ }^{2}} \cdot \bar{Q}+\left(\frac{1}{2 k_{2} \cdot \varphi_{2}^{2}}-\frac{1}{2 k_{1} \cdot \varphi_{1}^{2}}\right) \cdot \bar{Q}^{3}} .
\end{aligned}
$$


Умови стійкості многовиду стаціонарних режимів, отриманих на основі біфуркаційного аналізу (біфуркаційна множина (6)), узгоджуються й з чисельним інтегруванням.

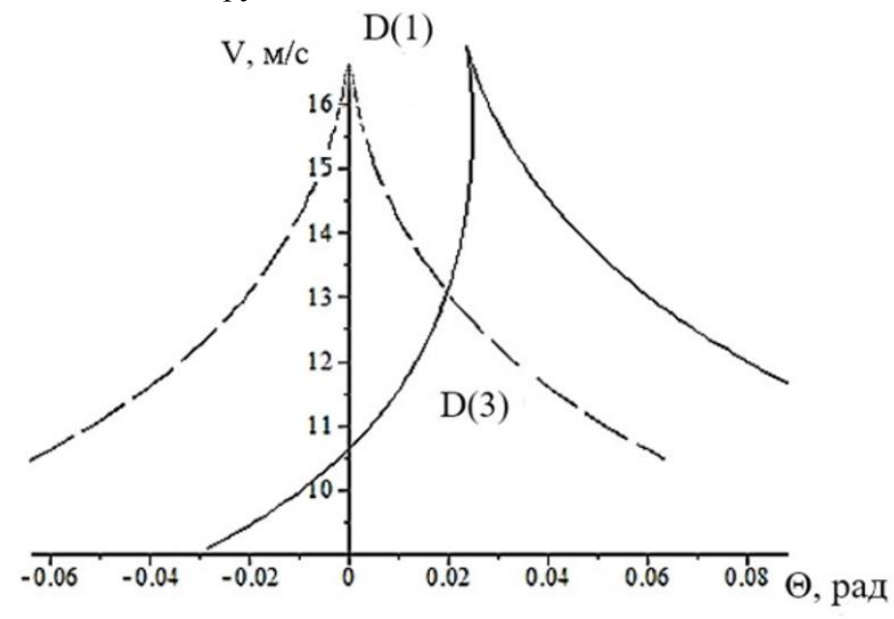

Рисунок 3. - Біфуркаційна множина у разі дії бічної сили

Конфігурація біфуркаційної множини у разі наявності постійного силового збурення (рис. 3 суцільна крива) не міняючись якісно в порівнянні з випадком $\bar{Q}=0$ (пунктирна крива), втрачає симетричність, що вказує на асиметрію властивостей лівого і правого поворотів.

В області D(3) є один стійкий стаціонарний режим і два нестійких, в області D(1) - один нестійкий. Вістрю відповідає трикратна особлива точка (режим $\bar{Y}=0$ ), в площині параметрів точка з координатами

$$
\theta^{+}=\frac{g \cdot l \cdot \bar{Q}}{V^{+2}}, \quad V^{+}=\left(\frac{k_{1} \cdot k_{2} \cdot g \cdot l}{k_{1}-k_{2}}\right)^{1 / 2}
$$

\section{ОБГОВОРЕННЯ РЕЗУЛЬТАТІВ ДОСЛІДЖЕНЬ}

Як випливає з проведеного аналізу, при досить малих збуреннях $\bar{Q}$ критичні значення параметрів управління прямолінійного режиму (двократного) i $\left(\theta^{+}=\frac{g \cdot l \cdot \bar{Q}}{V^{+2}}=\frac{k_{1}-k_{2}}{k_{1} \cdot k_{2}} \cdot \bar{Q} \approx G(\bar{Q})\right)$ мають спільну границю.

Нульовому куту повороту коліс $(\theta=0)$ відповідають кругові стаціонарні режими, дивергентна втрата стійкості відбувається приблизно при швидкості $\mathrm{V}_{+}=10,5 \mathrm{M} / \mathrm{c}$. На рис. 4 представлено результати чисельного інтегрування системи при швидкості $\mathrm{V}=10 \mathrm{M} / \mathrm{c}$ (неперервна крива - коло), $\mathrm{V}=11 \mathrm{M} / \mathrm{c}$ (пунктирна крива спіралеподібна, відповідає нестійкому руху).

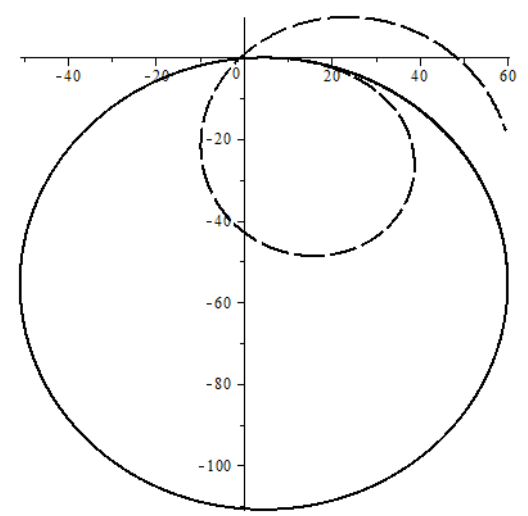

Рисунок 4. - Траєкторія центру мас моделі екіпажа при докритичній швидкості $V=10$ м/c (неперервна крива) і при закритичній швидкості $V=11 \mathrm{M} / \mathrm{c}$ (пунктирна крива). 
Стійкий стаціонарний режим, що відповідає набору параметрів з області $\mathrm{D}(3)$, при неперервній повільній зміні параметрів управління залишається стійким, доки точка в площині параметрів керування не перетне біфуркаційну криву. Точкам площини параметрів з області $\mathrm{D}(1)$ відповідають лише нестійкі стаціонарні режими.

Така загальна картина дивергентної втрати стійкості характерна для моделі екіпажа 3 надлишковою повороткістю $k_{2}<k_{1}$ (умова для безрозмірних коефіцієнтів відведення на осях). Співвідношенню параметрів $k_{2} \cdot \varphi_{2}^{2}<k_{1} \cdot \varphi_{1}^{2}$ відповідає випадок небезпечної втрати стійкості в сенсі М.М. Баутіна (характеризується необмеженим зростанням збурень фазових змінних) [8]. Умова $k_{2} \cdot \varphi_{2}^{2}>k_{1} \cdot \varphi_{1}^{2}$ відповідає безпечній втраті стійкості в сенсі М.М. Баутіна - зростання збурень фазових змінних обмежене.

Чисельні розрахунки виконано для наступного набору конструктивних параметрів екіпажа: $m=2717$ к2, $I=4061 \kappa 2 \mu^{2}, a=1,14 \mu, b=1,6 \mu, k_{l}=1177200 \mathrm{H} / \mathrm{paд}, \mathrm{k}_{2}=103500 \mathrm{H} / \mathrm{paд}, \varphi_{1}=\varphi_{2}=0,8$.

\section{ВИСНОВОК}

Проведено аналіз дивергентної втрати стійкості нелінійної моделі колісного екіпажа при наявності постійного силового збурення на основі біфуркаційного підходу, що дає можливість визначити інтегральну картину дивергентної втрати стійкості всього многовиду стаціонарних станів системи у вигляді біфуркаційної множини. Показано, що вплив постійного силового збурення призводить до втрати симетрії біфуркаційної множини, але при цьому не змінюється іï якісна структура - наявність каспу (відповідає трикратному круговому режиму); досліджено умови реалізації катастрофи метелик (відповідає п'ятикратному режиму), що змінює стан безпечної-небезпечної втрати стійкості трикратної особливої точки; визначена в загальному вигляді нелінійна функція корекції кута повороту керованих коліс екіпажа для відновлення прямолінійного руху (при умові існування обернених залежностей сил відведення на осях екіпажа); показано, що при лінеаризації сил відведення функція корекції кута повороту керованих коліс співпадає 3 раніше отриманим відомим результатом.

\section{ПЕРЕЛІК ДЖЕРЕЛ ПОСИЛАННЯ}

1.Fabio Della Rossaa, Giampiero Mastinub, Carlo Piccardia. Bifurcation analysis of an automobile model negotiating a curve. Vehicle System Dynamics, Vol. 50, No. 10, 2012. - pp. 1539-1562.

2.Постон Т., Стюарт И. Теория катастроф и ее приложения.- М.: Мир, 1980. - 607c.

3.Verbitskii, V. G., Lobas, L. G. Bifurcations of steady states in systems with rolling under constant force perturbations. Journal of Applied Mathematics and Mechanics, № 58(5), 1994. - pp. 933-939.

4.Verbitskij, V. F., Lobas, L.G. Nonlinear stability and bifurcation sets of the stationary states of wheel robots under control parameters change, Problemy Upravleniya I Informatiki (Avtomatika), № 3, 1996. - pp. 35-51.

5.Лобас Л. Г. Качественные и аналитические методы в динамике колесных машин. Киев: Наукова думка, 1990. - $216 \mathrm{c}$

6.Эллис Д. Р. Управляемость автомобиля. М.: Машиностроение, 1975. - 216 с.

7.Kwatny H.G., Chang BC., Wang SP. Static Bifurcation in Mechanical Control Systems. In: Chen G., Hill D.J., Yu X. (eds.) Bifurcation Control. Lecture Notes in Control and Information Science, vol. 293. Springer, Berlin, Heidelberg, 1993. - pp. 67-81.

8.Баутин Н.Н. Поведение динамических систем вблизи границ области устойчивости. М.: Наука, 1984 - 176 c.

\section{REFERENCES}

1.Fabio Della Rossaa, Giampiero Mastinub, Carlo Piccardia (2012) Bifurcation analysis of an automobile model negotiating a curve. Vehicle System Dynamics Vol. 50, No. 10, pp. 1539-1562.

2.Poston, T., Stewart, I.(1980) Catastrophe Theory And Its Applications. Moscow: Mir, 607 p.

3.Verbitskii, V. G., Lobas, L. G.(1994). Bifurcations of steady states in systems with rolling under constant force perturbations. Journal of Applied Mathematics and Mechanics, № 58(5), pp. 933-939.

4.Verbitskij, V. F., Lobas, L. G. (1996). Nonlinear stability and bifurcation sets of the stationary states of wheel robots under control parameters change, Problemy Upravleniya I Informatiki (Avtomatika), № 3, pp. $35-51$.

5.Verbitskii, V. G., Lobas, L. G. (1990). Qualitative and analytical methods in the dynamics of wheeled vehicles Kachestvennye i analiticheskie metody v dinamike kolesnykh mashin], Naukova Dumka, Kyiv, 216 p.

6.Ellis J. R. (1975). Vehicle Dynamics. - Mashinostroenie, Moscow, - 216 p. (Russian translation).

7.Kwatny H. G., Chang B.C., Wang SP. (2003). Static Bifurcation in Mechanical Control Systems. In: Chen G., Hill D. J., Yu X. (eds) Bifurcation Control. Lecture Notes in Control and Information Science, vol 293. Springer, Berlin, Heidelberg, pp. 67-81.

8.Bautin N. N. (1984). Behaviour of Dynamical Systems near the Boundary of the Stability Domain. Nauka, Moscow. -176 p. 


\begin{abstract}
V. Verbitskii, V. Khrebet, Y Misko A bifurcation approach to analysis of divergent loss of stability of a nonlinear wheeled vehicle model with constant force disturbance

A bifurcation approach to the analysis of the divergent loss of stability of a nonlinear model of a biaxial vehicle in case of constant force disturbance is presented. With proper correction of the steering angle of the steered wheel module, the vehicle returns to a stable rectilinear movement. The dependence of the steering angle on the lateral perturbation is presented in the paper (the control function significantly depends on the nonlinear characteristics of the forces slip of the vehicle model). In linear lateral forces slip the proposed control function coincides with the known ratio obtained by a number of authors. Based on the bifurcation approach, which does not require prior determination of the set of stationary states of the vehicle model, an appropriate method of constructing a critical set of control parameters was implemented (longitudinal speed and the steered wheels angle). When intersecting the critical set of parameters, there is a divergent loss of stability of the stationary mode, which is guaranteed to be stable until the moment of reaching the critical values of the control parameters. The critical set of parameters has a point of sharpening, within a small vicinity of which this critical set can be represented analytically by a semicubic parabola. When changing significant design parameters, the critical set of parameters is transformed, this is associated with a change in the nature of the safety of rectilinear motion stability loss. It is shown that the condition of safe-dangerous loss of stability of straight-line motion is determined by the ratio between dimensionless coefficients of slip on the vehicle axes and the coefficients of clutch on the axes of the vehicle in the transverse direction. Therewith, coefficients of clutch are not included in the linearized system of perturbed motion equations, but refer to a substantially nonlinear characteristic of the forces slip.
\end{abstract}

Keywords: dynamic system, wheeled vehicle, steady-state conditions, stability, divergent bifurcations

ВЕРБИЦЬКИЙ Володимир Григорович, доктор фізико-математичних наук, професор, завідувач кафедри програмного забезпечення автоматизованих систем, Запорізький національний університет е-таil: verb@zsea.edu.ua https://orcid.org/0000-0002-1039-8548

ХРЕБЕТ Валерий Григорович, кандидат физико-математичних наук, доцент кафедри прикладної математики, Національний авіаційний університет, e-mail: v.khrebet@ nau.edu.ua https://orcid.org/0000-0002-0191$\underline{1768}$

МІСБКО Євген Михайлович, старший викладач кафедри машинобудування, Одеської державної академії будівництва та архітектури, e-mail: dreadfull87@gmail.com ORCID: 0000-0002-9020-5266

Volodymyr VERBITSKII, Doctor of Physical and Mathematical Sciences, Professor, head of Department of Software Automated Systems, Zaporizhzhya National University: e-mail:_verb@zsea.edu.ua https://orcid.org/0000$\underline{0002-1039-8548}$

Valeriy KHREBET, Candidate of Physical and Mathematical Sciences, Associate Professor of the Department of Applied Mathematics, National Aviation University, e-mail: v.khrebet@nau.edu.ua https://orcid.org/0000-0002-0191$\underline{1768}$

Yevgen MISKO, senior lecturer of Department of Mechanical engineering, Odessa State Academy of Civil Engineering and Architecture, Odessa, dreadfull87@ gmail.com ORCID: 0000-0002-9020-5266

DOI 10.36910/automash.v1i14.345 